\title{
How will a conceptualized GCE curriculum function within Chinese secondary schools?
}

\author{
Yi Hong ${ }^{1}$
}

Accepted: 20 November 2021

(C) UNESCO IBE 2022

\begin{abstract}
Global citizenship education (GCE) advocates global interdependency and interconnectedness, encouraging students to actively defend social justice, equity, and sustainable development at both local and global levels. When putting GCE into use, educators need specifications to transform it from normative ideals into knowledge suitable for conceptual learning. This case study explores Chinese educators' views on GCE regarding operationalized intents, practices, and preparation for implementation in a curriculum. It aims to understand how the conceptualization of GCE functions as a curriculum innovation at secondary school level. Principals $(n=6)$ and teachers $(n=10)$ from six participating schools in an anonymous city in Jiangsu province were purposely sampled, providing data for the researcher in semistructured interviews. The study reveals a GCE curriculum prototype in which the intents were subject to Confucian values and Moral Education's disciplines, whereas pedagogies and instructional approaches were planned to be consistent with constructivist teaching and delivered in an authentic learning context.
\end{abstract}

Keywords Global citizenship education · Chinese secondary schools · Curriculum studies $\cdot$ Moral education

The disastrous mortality rate of Covid-19, along with the accompanying psychological trauma, socioeconomic inequality, and racial conflicts that exploded in the persisting context of political division and dysfunction, have exposed us all to the risks of a polarized mindset (Raskin, 2020). We are living in a time that makes it clear we need to break away from extremism. In early 2015, a UNESCO document offered normative guidance for youth development in quality education: a project called global citizenship education (GCE), which aims for sustainable progress by 2030. A global citizen has "a sense of belonging to a broader community and common humanity. [GCE] emphasizes political,

Yi Hong

yihong8199@suda.edu.cn

1 School of Education, Soochow University, Dushu Lake Campus, Suzhou 215123, Jiangsu, China 
economic, social and cultural interdependency and interconnectedness between the local, the national and the global" (UNESCO, 2015, p. 14).

As an overarching statement, this normative standard of achieving interdependency and interconnectedness requires clarification. Torres and Bosio (2020, p. 104) described GCE as "an essential tool to not only build understanding across borders and cultures but to advance our social, political, economic, and environmental interconnectedness necessary to address global and local issues". This definition relates to GCE's critical awareness of power inequality. Parallel to the call for critical awareness, many cases across the world suggest that advocacy-oriented concepts of GCE can contribute to more comprehensive and tangible teaching (Cho \& Mosselson, 2018; Hammond \& Keating, 2018; Howard et al., 2018). These cases demonstrate "reverse outcomes of reinforced neoliberalism and post-colonialism" when social justice and equity were not prioritized (Hong, 2020, p. 456). Therefore, the literature also offers evidence of GCE increasing student agency toward becoming active citizens (Andreotti, 2006; Davies, 2006). Despite GCE's importance, teaching to achieve this aim is difficult. Complexities lie in the ambiguity of the core knowledge and the model that can support the learning progression of this knowledge (Jerome \& Lalor, 2020; Ryen \& Jøsok, 2021).

A previously published article found that six secondary schools on the east coast of China selected a competency-based model to promote GCE (Hong, 2020). However, since a competency framework lacks the epistemic basis (Ryen \& Jøsok, 2021), we need more information to understand educators' rationale in conceptualizing GCE for practice in empirical settings. I applied grounded theory to collect data from the same case schools via semistructured interviews with principals $(n=6)$ and teachers $(n=10)$. The results showed that GCE is processed as a cultural construct, although in a conflicted manner, to be operationalized in an authentic learning environment. The convergence of a moral approach and a constructivist approach inevitably contrasts with GCE based on competency-based education, which was preferred by participants.

\section{The likely role of Global Citizenship Education in the curriculum}

For school educators, working with GCE requires seeking compatibility between this novel form of education and their current curriculum. For instance, in the UK, GCE conflicted with fundamental British values in teacher education, which led teachers to display different attitudes toward GCE and fundamental British values, including comfort, compliance, criticality, and critical being (Bamber et al., 2018).

To reap the maximum benefits of GCE, school educators need to consider GCE's role within and relationship with national citizenship identity. The literature cites at least three advantages of GCE. First, GCE may assist in teaching topics related to conflicts involving immigration (Banks, 2008; Tarozzi \& Torres, 2016; Zhou, 2011), religion (McKinney, 2008; Niens \& Reilly, 2012), and racial riots (Ho, 2009). In this regard, GCE is an umbrella term for multicultural and intercultural education. Second, GCE may help raise students' awareness of critical values. GCE has been designed for anticolonial purposes in a Ghanaian secondary school, although this aim has not yet succeeded (Howard et al., 2018). Third, GCE aims to teach students to be more employable. A case study in Japan revealed that GCE follows neoliberal objectives to increase employability with a strengthened notion of ethnic identity (Hammond \& Keating, 2018). However, the notion of employability conveyed in GCE often suffers from the downsides of neoliberalism, such 
as worsening socioeconomic inequality (Cho \& Mosselson, 2018; Hammond \& Keating, 2018; Howard et al., 2018).

Across countries and despite different opinions, GCE is generally viewed as being incorporated through loosely scaffolded programs in informal curricula and extracurricular activities. For example, GCE is associated with global disposition, which is often regarded as an additional topic of citizenship education (Reynolds et al., 2015). It bears similarities to the program provided by the Center for Civic Education in the US (Gaudelli, 2009). Moreover, GCE can appear in the form of extracurricular activities, such as cultural exchange, volunteering, or study-abroad programs. Wynveen and colleagues (2012) studied the efficacy of a 4-week study-abroad program in enhancing US students' pro-environmental behavior, and they found that the short study-abroad experience nurtured students' justice-oriented global citizenship and promoted a broader worldview and responsibility for environment. However, although an informal curriculum may be one method for students to attain GCE, there is no conclusive evidence to date of its effects on all youth in different curricular designs. As reported in Australia-based research, GCE is marginalized despite being linked with cross-curriculum priorities and general capacities (Buchanan et al., 2018; Print \& Buchanan, 2019).

The approach reflected above seems to overlay the pedagogies used in civics and citizenship education (CCE). The literature highlights the teaching and learning of CCE in informal curricula, which focus on supporting civic engagement, developing social capital, and enhancing language agency (Niemi \& Chapman, 1999; Print, 2007; Youniss et al., 1997). These qualitative changes may also apply to students involved in GCE, which Ertmer and Newby (1993) indicate as a constructivist approach. A variety of teaching strategies are recommended for such approaches, including class voting, group inquiry, cooperative learning, informed and critical discussions with students, linking practices in different domains, attention to students' identities, professional preparation, and issue-based model learning combined with cognitive training (Patrick, 1999; Print, 2007; Torney-Purta, 2002).

Thus, despite being aware of many important curriculum elements (e.g., curriculum goals, curriculum types, and pedagogical strategies), we still lack clarity regarding what causes GCE to be different from one context to another. In particular, it is not clear how knowledge of and approaches to the teaching of GCE function in relation to local conditions. The answer to this question may help us understand what contributes to the current imbalanced development of GCE. I argue here that by tracing educators' steps of decisionmaking in curriculum development, one can obtain their lines of reasoning as evidence.

The literature indicates at least three different rationales to explain contextually different planning of the knowledge and learning progression of GCE, all of which contain hurdles. First, from the aspect of constructivism, educators make decisions to deliver knowledge as content for emancipation. Jerome and Lalor (2020) found that students usually have a politically naïve understanding of the world before progressing to the concepts of power and agency, and some students develop a more nuanced conception of power and agency in relation to complex chains of influence. Moreover, this learning progression fits a qualitative "expansion", rather than "addition", model of enhancing reasoning. However, such qualitative progression could hardly be planned and assessed through Piagetian or other staged models (Jerome \& Lalor, 2020). Additionally, the transmission of values is embroiled with Moral Education (Jerome \& Lalor, 2020), which introduces more complexities into teaching, such as the challenges of understanding different students' nonlinear, dynamic moral development (contrasting Kohlberg's staged model) and of breaking the “cultural difference/universal commonalities" dichotomy (Kim, 2015, p. 66). 
The second rationale comes from a more critical perspective: educators ensure knowledge serves as an agent for emancipation. Through achieving independence from pre-existing social orders via subjectification, knowledge shall "[set] in motion a dialectical process of reflection that also plays a part in the formation of the subject" (Ryen \& Jøsok, 2021, p. 14). In this regard Biesta says that learning progression is "from the self and returns to the self" (2016, p. 376). Echoing the Bildung-centered Didaktik of Scandinavian/German education, this approach requires teachers to seek critical pedagogical choices beyond those provided by the curriculum. They also show more flexibility in deciding subject contents so that they can cope with different lines of reasoning, by students and themselves, and form arguments (Ryen \& Jøsok, 2021). This method could challenge teachers who are unfamiliar with the Bildung tradition and thereby reduce the learnability of GCE in a different cultural context.

Finally, from a pragmatist perspective, which is the third rationale, GCE is often acknowledged via a competency-based framework. Hong (2020) conducted a situational analysis through a selected case of six secondary schools on the east coast of China and found GCE implemented through competency-based education. However, based on the results of the situational analysis, GCE only offers subtle benefits to competency-based education-unsurprising given that a competency framework lacks the epistemic foundation (Ryen \& Jøsok, 2021) for guiding teaching. As Table 1 shows, this research case involved students with low socioeconomic status, and the schools prioritized improving academic performance to ensure social mobility (Hong, 2020). Asian societies that emphasize Confucianism tend to value meritocracy along with the moral aspect of GCE. This seems to be the case for GCE in the Chinese context. But why is this pragmatic perspectivism so widely accepted despite its ineffectiveness? Dissatisfied with the preliminary conclusion that GCE was constructed via competency development, I aimed to learn more about participants' conceptualization of the exact knowledge and methods of teaching GCE in a more empirical curricular setting. This, therefore, is the primary focus of the present study.

\section{Context of GCE in Chinese secondary schools}

At the secondary school level, Moral Education dominates China's educational practices related to identity development. Since 2017, the textbook series Morality and Law has been used nationwide for grades K through 9. Supplementing unified teaching is a highly bureaucratic internal governance advocating compliance with Moral Education (Hong, 2019). Moreover, the school culture in China is heavily laden with moral objectives (Yang, 1990). Even civic literacy has been greatly emphasized; implemented within a culturalist framework, it is converted into virtues to cultivate citizens' sense of obligations and to develop "fighters who contend with systems continuously to achieve rights" (Ban \& Tan, 2015, p. 98).

As suggested by $\mathrm{Yu}$ (2014), it is also likely that using GCE to introduce new virtues on human interactions and relationships constitutes a moral approach of integrating GCE into Moral Education. However, the feasibility of such an approach is questionable. Since this context lacks a critical account of power and agency, practices in it can fall short of the aim of virtue cultivation, which requires transitioning from a lower-level individual or interpersonal mode of reasoning into discussion with respect to moral principles (Jerome \& Lalor, 2020). Research has found that Chinese students display prosocial behavior only 


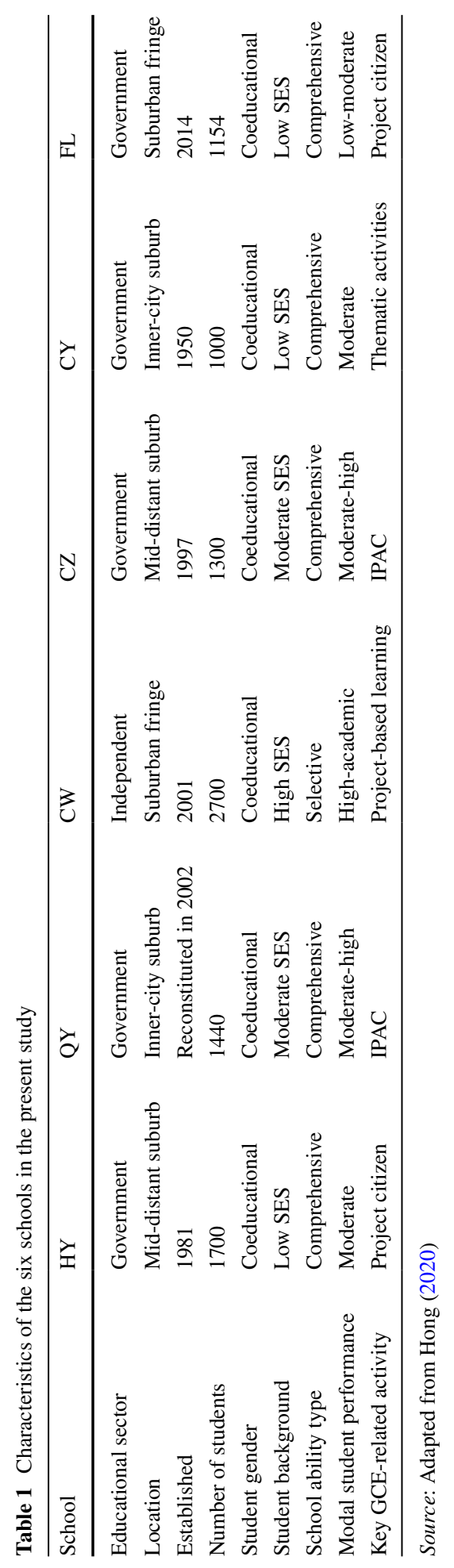


when interacting with peers but are much less likely to react beyond culturally approved behaviors (Lee, 1997; Li et al., 2012).

In empirical settings, GCE has been contextualized in China in a highly contested way. GCE-related interpretations are not consistent in curriculum documents, local research, and educational practices (Hong, 2020). The listed requirements relating to GCE in curriculum documents contain conflicting ideologies, and local scholars theorize GCE with opposing ideas. Local educators suggest combining GCE with competency-based education (rather than Yu's moral approach [2014]) as a middle way to resolve controversies. This approach includes the learner-based Integrated Practical Activity Curriculum (IPAC); outsourcing resources from nongovernmental organizations, foreign institutions, and grassroots groups; and extracurricular activities intended to develop global perspectives (Hong, 2020).

However, this competency model for GCE encounters challenges. Local literature criticizes Chinese teachers' inability to provide student-led learning activities. Though local schools have introduced many student-centered pedagogical strategies since the 1920s, the underlying educational philosophies were not integrated, thus leaving the conservative approach to teaching unchanged (Yang, 2004, p. 147). Teachers are usually unaware of or unable to execute strategies tailored to the content and situation of teaching associate student agency, such as switching their dominant roles to facilitators (Tan \& Zhou, 2004). This point is manifested through the failure of the IPAC, which is arguably less effective due to poorly developed curriculum resources (Zheng, 2008). Moreover, several academics doubt whether the nationalism-oriented national curriculum would assimilate citizenship education into another version of political-ideological education (Zhao, 2013). Participants in this Chinese case also reflected that their professional disciplines prioritized efficiency and drove them to be deeply committed to the subject content, values in the formal curriculum, and professional training (Hong, 2020). Consequently, doubts remain about participants' perceived knowledge and experience of teaching GCE, and these doubts set the starting point for the present research.

\section{Methodology}

As part of a doctoral project, this study adhered to the constructivist grounded theory methodology (Charmaz, 2006), which was also applied in a previously reported case (Hong, 2020). To obtain participants' opinions, I designed the present study as a thought experiment-first created by Hans Freudenthal as part of development research to allow the cyclic process between obtaining knowledge through a prototype and practice (Gravemeijer, 1994)—where I encouraged participants to actively imagine a GCE curriculum in reality.

In meeting participating schools' preferences for competency-based education, I adopted Oxfam's definition of GCE (2015) as the guiding definition since it contains a more explicit message on the desired learning outcomes, and I intend to explore what specifications may need to be converted into knowledge for different learning stages. A byproduct of this study was a potential plan for integrating GCE into existing practices.

In 2017, I obtained ethical approval for the data collection procedure from the Human Research Ethics Committee of the University of Sydney. Following the recommendation from the local education bureau, I employed purposive sampling to recruit school principals $(n=6)$ from six chosen schools in a second-tier city in Jiangsu Province, China (Table 1). Based on several considerations, these schools were chosen as being representative of typical secondary schools located in a moderately developed city on the east coast 
of China, including students' socioeconomic backgrounds and academic performances, the school types, and their activeness in implementing an informal curriculum related to GCE.

The principals from each school recommended two teachers as teacher participants. Most teacher participants were Moral Education teachers, as they primarily bear the responsibility for implementing informal curricula. In HY secondary school, the principal also recommended a mental health teacher who offered support for all-around development. Background details of the teachers $(n=10)$ were also obtained (Table 2$)$, including their career stages and subjects.

I arranged face-to-face, semistructured interviews with participants to collect data. Interview questions were adapted from Lee and Leung (2006). Data were transcribed and analyzed in Chinese with the assistance of NVivo11, following Neuman's (2014) approach to conceptualization, coding, memo writing, and outcropping. The analysis is abductive, which follows a general instrumental guidance in curriculum development theory (Print, 1993, p. 84), based on which evidence is substantiated within the basic structure of the curriculum to demonstrate the knowledge and the learning progression conceptualized by participants.

\section{Findings}

\section{Curriculum intents}

In this Chinese case, educators favored working hypotheses of GCE, and they preferred these hypotheses to be concrete, specific, value-neutral, and able to be taught in a technical way. In the opinion of a few participants (Teacher Z, CZ; and Principal B, HY), GCE meant an empty idealism too distant to achieve. Most participants, though, were insensitive to the highly abstract and general definitions in international GCE discourses. They viewed various definitions bearing slightly different ideologies as "about the same" (Teacher W, QY), and said they "didn't think that much [about it] before" (Teacher J, CW). As will be elaborated on in this section, three themes emerged regarding the intent of a GCE curriculum plan: complying with the standards in official documents, giving Chinese cultural identity precedence over global identity for development, and ensuring values advocated in GCE were consistent with those of Moral Education.

First, participants confirmed the two key sources of standards they used as guidance for complying with the national curriculum. The first source was the Core Competencies and

Table 2 Participants in the present study

\begin{tabular}{lllllll}
\hline Schools & HY & QY & CW & CZ & CY & FL \\
\hline Principals & Principal B & Principal U & Principal C & Principal W & Principal Y & Principal Z \\
Teachers* & Teacher A & Teacher W & Teacher J & Teacher L & Teacher H & Teacher F \\
& (Junior; ME) & (Junior; ME) & (Junior; ME) & (Senior; ME) & (Senior; ME) & (Senior; ME) \\
& Teacher T & & & Teacher Z & Teacher C & Teacher M \\
& (Junior; MH) & & & (Senior; ME) & (Senior; ME) & (Junior, ME) \\
\hline
\end{tabular}

Source: Hong (2020)

* Junior $=$ three or fewer years of teaching; senior $=$ more than three years of teaching; ME = Moral Education subject; $\mathrm{MH}=$ mental health subject. 
Values for Chinese Students' Development, which includes aims such as self-development (learning to study, leading a healthy life), civic participation (being responsible, practicing innovation), and culture infrastructure (appreciating cultural heritage, developing a scientific mindset). The other source of standards was the national curriculum, which includes restrictions in terms of knowledge (understanding basic national conditions, fundamental ideologies, national policies, and overview of the world), skills (developing the skills of observing, feeling, experiencing, and participating in civic life; forming preliminary skills of engaging and communicating with others), and virtues and dispositions (loving the socialist motherland and loving peace, yet also having global perspectives).

The second theme was based on the participants' strong intention to preserve Chinese cultural identity in GCE and defend Chinese culture from assimilation. The reasons for supporting this principle include "cultural solidarity is essential" (Teacher J, CW), "traditional culture and universal value can find compromise" (Principal Y, CY), "global awareness should not entail sacrificing the local culture" (Principal Z, Teacher F, Teacher M, FL), and "understanding Chinese culture helps to set the basis for conducting comparative studies across other countries" (Principal U, QY). Moreover, as reflected in participant responses, preserving cultural identity helps to form an international perspective, though selectively. Teacher F from FL secondary school commented:

We need to guide students to think logically, to absorb the good things from the foreign culture - we should learn without an arrogant attitude - and to discard the bad things that do not fit into our country's conditions appropriately, as every country has its specific conditions.

The third theme stemmed from the participants' understanding that supporting Moral Education equaled supporting GCE. For instance, nearly all participants mentioned the Confucian virtue of being responsible for social relations as an overlapping virtue in GCE. Principal U (QY) explained:

In Chinese traditional culture, there is a significant concept called filial piety, which is the foundation of all other virtues.... When you have faith in filial piety, you will have humanity, and you will know how to get along with others.... By extending the love for your own parents to other elderly people, and extending the love for your own children to other children, isn't that a way of intensifying the relationships? The essence of traditional culture is treating others as you would like them to treat you.... When we have awareness of the law and reciprocal respect, and the idea of not fighting for their interests, the world will embrace peace.

Moreover, in the context of Confucianism, participants endeavored to advocate the concepts of the rule of law, participatory democracy, and civil society, going beyond Confucianism. Principal W (CZ) said:

[Students] should stand on the side of justice and should have their values while they obey the rules. Then they will know how to understand the society, including the people around [them] and themselves....various conditions might differ from the condition in China. Some are found in Eastern countries, some in Western countries, and even in the Western countries, there are also diverse situations, so it is better to know all this knowledge around the world. The more the better.

Finally, it is also notable that teacher participants favored their current disciplines, regarded as part of Moral Education. These included highly disciplined hairstyles (e.g., not dyeing one's hair), dress code (e.g., wearing school uniforms), and polite behavior in public (e.g., 
ethical tourism). They held the belief that students who were disciplined and civic-mannered in Chinese culture would be welcomed in different cultural surroundings.

\section{Curriculum practices}

Participants already had some ideas about teaching GCE. They agreed upon and emphasized the effectiveness of a student-led learning strategy, where students' feelings, thoughts, personal ethos, and private experiences are involved to create an authentic learning environment (Reigeluth \& Keller, 2009). They mentioned the effectiveness of various pedagogies, including group discussion, voting, observation, role playing, and debating. Moreover, teachers emphasized the importance of letting students learn firsthand, intuitive facts. One suggested that "the best politics class should be an open environment" (Teacher $\mathrm{L}, \mathrm{CZ}$ ), referring to learning beyond textbooks and internet searches.

Nevertheless, teachers often found themselves unable to help students obtain satisfying materials. They believed they would continue to implement the current teaching-learning strategies, feeling they could not easily change anything in the educational system. Based on this consensus, participants suggested using school-oriented informal curricula for Year 7 and 8 students and a subject approach for Year 9 students for GCE in secondary school education. They viewed these as the most likely practices that schools could incorporate. Furthermore, since an authentic learning environment sets challenging teaching requirements, participants provided a series of suggested actions in response to different situations (see "Curriculum differentiation").

\section{Years 7 and 8: Varied training through the school-oriented informal curriculum}

Outsourcing programs were the resources for GCE in Years 7 and 8. Notably, all participants in the chosen middle schools considered International Understanding Education the ideal model. The program was based on intercultural exchange programs, such as the American Field Service. In these programs, students were required to cover all expenses when they were abroad. Of the six schools, only $\mathrm{CW}$ middle school saw a reasonably high number of students participating in International Understanding Education, while the other five community schools saw only a few students registered in relevant programs each year. Nevertheless, most participants had opinions similar to Principal Z (FL):

To be honest, the best way of having students integrated into one [foreign] ethnicity or one [foreign] country is to let them go abroad and experience the homestay in foreign countries.

In addition, many participants from the public schools referred to Project Citizen as a safe substitute for GCE. It includes project-based learning, poster presentations, and a mock Congressional hearing. In FL secondary school, which has implemented Project Citizen for many years, participants recommended replacing local community-related research topics with international affairs (e.g., environmental protection and resource utilization) to realize GCE. Similarly, Teacher A (HY) suggested using Project Citizen to conduct comparative research on smog issues in America, Britain, and China. Teachers in CZ secondary school proposed projects on studying etiquette in different countries as a substitute for GCE. Teacher L (CZ) reflected: 
We have been advising the teaching researchers of the Moral Education subject. What is the point of continuing the old way of teaching the politics class? It will be more valuable to adopt the approach of implementing Project Citizen.

Project Citizen could be a promising avenue for advancing project-based learning with secondary schools from other countries. Participants favored the idea of bringing their students to collect firsthand data for projects. However, this did not guarantee that teachers would allow students to conduct projects on controversial or politically sensitive topics. One teacher said:

Some issues of GCE are too complex for secondary school students to solve. We can lead them to think through these international issues, but usually, we will not lead them to investigate further. [Do you know] to what extent we wish to achieve through Project Citizen? We require students to not only think through the problems but also suggest solutions as the final output. Regarding the topics in GCE, it will be more practical for students to undertake some thinking and reflection, but difficult for them to generate some mature ideas.

Finally, it may be possible to convert GCE to a more learnable project in the IPAC. As an activity-based compulsory curriculum that is part of the national curriculum, the IPAC is characterized by project-based learning, community education, IT education, and labor education. It is driven by textbook requirements as the elective activities of each learning module and by student-initiated projects.

\section{Year 9: Drifting toward unification through the formal curriculum}

In Year 9, teaching GCE would drift toward unification, as most participants agreed to use Moral Education (the formal national curriculum) to implement GCE. According to participant responses, students in Year 9 were preoccupied with a heavy schoolwork load, and therefore it would be better to focus on the formal curriculum. Moreover, teacher participants stated that the contents and instructions of Year 9 Moral Education covered world topics, and that their training to obtain a teaching degree prepared them to present these.

\section{Curriculum differentiation}

Participants adopted differentiated curricula to meet students' varied backgrounds and capabilities. The major reason they gave was that it challenged the educational goals for teaching international issues to students from lower socioeconomic backgrounds (Table 1). Principal B (HY) reflected:

I think, in addition to making contributions to the country within your capability, which is the most basic requirement, you can devote some efforts to global development when you have the abilities. If it is higher than a student's actual ability, he will not be able to accomplish that. It will be impossible for him, won't it?

As a result, with the exception of educators in CY secondary school, other participants favored the thematic activities approach to delivering GCE, which prepares students for the local job market as well as participation in the local community. These thematic activities were an umbrella term for informal and extracurricular activities under the titles Legal Education, Civilized Manners Education, Patriotic Education, and Community Education. 
Another differentiation strategy was to involve struggling students in activities of passive-cognitive learning, including, according to interview data, "involvement of a foreign teacher" or "a collection of GCE lectures delivered by experts". In contrast, some employed the strategy of involving high-achieving students in more challenging "schoolbased elective units based on teachers' and students' interests" and "societies and clubs". For example, in CW secondary school, where students had more advanced English abilities, Model United Nations was successfully implemented. However, this society achieved little success in other participating schools since it required students to debate international issues in English. Inevitably, GCE was depicted as an exclusive, rather than inclusive, learning opportunity.

\section{Preparation for implementation}

Teaching international issues is challenging when teachers lack systemic training. The primary reason is a lack of expert support. Most teacher participants admitted in the interviews that they had neither paid attention to world issues nor comprehended the exact meaning of GCE. In addition, in FL secondary school, the principal would only consider inviting GCE experts to the school to give speeches to replace teachers' roles.

The study also found controversy among participants regarding the evaluation and assessment of GCE. The minority, who proposed systematizing evaluations, concurred with the assertion that the key to developing moral competencies was repetitive training. They believed that GCE required long-term implementation to be effective (Teacher A, $\mathrm{HY}$; and Teacher Z, CZ) and that cultivating virtues required years of effort (Teacher F, FL; and Teacher H, CY). The majority believed that GCE constituted only a small part of students' encountered learning experiences at the secondary school stage. They considered experiences of going abroad, seeking life education, getting in touch with nature, and improving student learning environments as more effective strategies than providing only GCE-specific activities.

\section{Discussion}

Participants suggested a fully compatible version of a GCE curriculum as a supplement to the national curriculum. Its aims and goals in the prototype are consistent with those in the formal curriculum. It is likely that this fully compatible GCE curriculum would have only a subtle effect because of the overall Moral Education context. The present study accepted Yu's (2014) moral approach, which views some targeted skills as additional virtues in Confucianism. This stands as a contrast to conceptualizing GCE as a set of competencies in a preferred competency-based approach (Hong, 2020). Participants highlighted the paradox that a good Chinese citizen, ideally behaved, highly disciplined, and civic-mannered in Chinese culture, would automatically become a global citizen. Despite being acknowledged and emphasized, the international perspective suggested in this study fell short of its critical/advocacy-oriented meanings in the literature (Andreotti, 2006; Davies, 2006). Chinese educators in this Chinese case recommended an international perspective to gain cognitive knowledge of the basics of the world.

Moreover, the primary educational goal of GCE to preserve cultural identity is the same across all participating schools. The emphasis on cultural identity might echo the 
postcolonial value advocated in sub-Saharan Africa (Abdi, 2008; Howard et al., 2018). Nevertheless, the purposeful attempt to defend Chinese culture from assimilation seems to match Kohn's (1944) description of ethnonationalism "in budding stage" that emerged in Germany, Italy, and Slavonia at the beginning of the nineteenth century. The finding reflects the tendency that ethnonationalism-an ideology, Kohn calls it-could soon become an expansive desire for forming a nation-state, as long as the public gained more "growing strength" and "political and cultural [awakening]" (1944, p. 9). This finding also seems to support the contentions of several scholars that citizenship education is being turned into another version of political-ideological education (Zhao, 2013). In this regard, the Chinese case is comparable, to a lesser extent, to the situation in Singapore, where a curriculum advocating national cohesiveness parallels an international outlook (Ho, 2009).

However, the politics of ethnonationalism in curriculum intents had little impact on participants' views on curriculum practices. Participants conceptualized and arranged GCE curriculum practices in a manner resembling curricula elsewhere in the world. GCE would be available but not taught specifically (Abdi, 2008; Banks, 2008; Ho, 2009; McKinney, 2008; Niens \& Reilly, 2012; Tarozzi \& Torres, 2016; Zhou, 2011). Consistent with the literature on constructivist teaching and an informal curriculum (Ertmer \& Newby, 1993), the participants believed that a student-led authentic learning context would be ideal for integrating GCE. Their conceptualized GCE resembled the conceptualizations in contexts where GCE is manifested. Additionally, their suggested pedagogies of group discussion, voting, observation, role playing, and debating aligned with the pedagogies recommended in the literature (Patrick, 1999; Print, 2007; Torney-Purta, 2002). Moreover, participants supported a variety of relevant learning avenues for planning and integrating GCE. These avenues included International Understanding Education, Project Citizen (introduced by the US to a few Chinese secondary schools in 2006), and the IPAC, as well as thematic activities. Accepting strategies in global education and civic education to support studentled learning in GCE is a position at odds with the ideo-political discourse to defend local culture. The finding triangulates the previous situational analysis of these six secondary schools (Hong, 2020).

Furthermore, the curriculum intents had little influence on the strategies participants used for integrating GCE into routine teaching. In planning the curriculum differentiation of GCE content, student academic performance played an important role in predicting their ability to acquire skills. Participants' past experiences drove them to admit that GCE-related activities were mostly exclusive to high-achieving students. In other words, the emphasis on collective cultural identity in curriculum intents had been weakened by meritocracy: availability of GCE was vested in individual students based on academic performance. It seems that the emphasis on meritocracy drove them to accept a competencybased model for promoting GCE in the situational analysis (Hong, 2020).

Along with the weakening of ethnonationalism, neoliberalism diminished the political character in GCE referred to in international discourses. Similar to cases (Cho \& Mosselson, 2018; Hammond \& Keating, 2018; Howard et al., 2018) where neoliberalism diminished social justice and equity in GCE, neoliberalism seemed to heavily shape the local educational opportunities of GCE in the Chinese case. One must look at the situation from the disadvantaged students' side: participants do not consider GCE an appropriate approach to employability, believing it is not practical to students who lack opportunities to compete in the global job market. This perception has driven participants to neglect GCE. In this way, the Chinese case differed from the finding in Japan that GCE enhanced employability (Hammond \& Keating, 2018). 
As an alternative, participants suggested a mixture of standards-based and student-centered curriculum design, so that even struggling students would benefit from these learning opportunities. In particular, the contents of GCE were planned and integrated as alternative learning topics for use in the informal curriculum and extracurricular activities. Different pedagogical strategies were adopted regardless of their underlying educational philosophies (Yang, 2004, p. 147). Furthermore, such an arrangement concurs with the issue reported in the situational analysis (Hong, 2020) that GCE-related activities became sporadic and less systemic, and thus departed from the instructional design principles (Collins et al., 1989; Reigeluth \& Keller, 2009). It also overturned the nature of learning progression in social studies as being "expansion" rather than "addition" (Burn \& Durran, 2007, as cited in Jerome \& Lalor, 2020, p. 106) even though the modification was driven by the intention to consolidate available curriculum resources. Consequently, participants placed little emphasis on deepening the critical teaching of power and agency. Instead, for Year 9 students, they considered conceptual learning in the formal curriculum as a substitute for GCE.

Finally, participants expected a GCE curriculum to be more resourceful than their current ones. They wanted expertise and systemic training to strengthen their professionalism. This finding aligns with Cogan and Grossman's (2009) assertion that teachers who are not globally minded will encounter difficulties in implementing teaching. Moreover, participants had diverse perspectives on how to assess and evaluate GCE. Only a few participants believed that a GCE curriculum needed to be assessed and evaluated regularly to ensure effectiveness. The majority believed that if GCE constituted a meaningful learning experience, it would need no additional evaluation. Again, these findings reflect participants' ignorance of the nature of the learning progression in social studies (Burn \& Durran, 2007; Jerome \& Lalor, 2020).

In summary, although this study involves only a small sample of educators from the east coast of China, it makes it clear that, for many schools, a sociocultural framing of GCE may severely disrupt curriculum logic, leading to altered implementation outcomes. Nevertheless, this study has several limitations. Outliers were not fully discussed due to space limits. Different subgroups held conflicting views on GCE, which this paper did not examine. Furthermore, as most teacher participants specialized in Moral Education, a more holistic view was unavailable.

\section{References}

Abdi, A. A. (2008). Educating for human rights and global citizenship. SUNY Press.

Andreotti, V. (2006). Soft versus critical global citizenship education. Policy and Practice: A Development Education Review, 3, 83-98.

Bamber, P., Bullivant, A., Clark, A., \& Lundie, D. (2018). Educating global Britain: Perils and possibilities promoting "national" values through critical global citizenship education. British Journal of Educational Studies, 66(4), 433-453.

Ban, J. W., \& Tan, C. B. (2015). "Citizen" or "SIMIN": An analysis of secondary school student civic virtues in China from the perspective of modernization. In M. Print \& C. B. Tan (Eds.), Educating "good" citizens in a globalising world for the twenty-first century (pp. 33-48). Sense Publishers.

Banks, J. A. (2008). Diversity, group identity, and citizenship education in a global age. Educational Researcher, 37(3), 129-139.

Biesta, G. (2016). The rediscovery of teaching: On robot vacuum cleaners, non-egological education and the limits of the hermeneutical world view. Educational Philosophy and Theory, 48(4), 374-392. 
Buchanan, J., Burridge, N., \& Chodkiewicz, A. (2018). Maintaining global citizenship education in schools: A challenge for Australian educators and schools. Australian Journal of Teacher Education, 43(4), 51-67.

Burn, A., \& Durran, J. (2007). Media literacy in schools: Practice, production and progression. Paul Chapman Publishing.

Charmaz, K. (2006). Constructing grounded theory: A practical guide through qualitative analysis. Sage.

Cho, H. S., \& Mosselson, J. (2018). Neoliberal practices amidst social justice orientations: Global citizenship education in South Korea. Compare: A Journal of Comparative and International Education, 48(6), 861-878.

Cogan, J. J., \& Grossman, D. L. (2009). Characteristics of globally minded teachers: A twenty-first century view. In T. Kirkwood-Tucker (Ed.), Visions in global education (pp. 240-270). Peter Lang.

Collins, A., Brown, J. S., \& Newman, S. E. (1989). Cognitive apprenticeship: Teaching the crafts of reading, writing, and mathematics. In L. B. Resnick (Ed.), Knowing, learning, and instruction: Essays in honor of Robert Glaser (pp. 453-494). Lawrence Erlbaum Associates.

Davies, L. (2006). Global citizenship: Abstraction or framework for action? Educational Review, 58(1), 5-25.

Ertmer, P. A., \& Newby, T. J. (1993). Behaviorism, cognitivism, constructivism: Comparing critical features from an instructional design perspective. Performance Improvement Quarterly, 6(4), 50-72.

Gaudelli, W. (2009). Heuristics of global citizenship discourses towards curriculum enhancement. Journal of Curriculum Theorizing, 25(1), 68-85.

Gravemeijer, K. P. E. (1994). Educational development and developmental research in mathematics education. Journal for Research in Mathematics Education, 25(5), 443-471.

Hammond, C. D., \& Keating, A. (2018). Global citizens or global workers? Comparing university programmes for global citizenship education in Japan and the UK. Compare: A Journal of Comparative and International Education, 48(6), 915-934.

Ho, L. C. (2009). Global multicultural citizenship education: A Singapore experience. The Social Studies, $100(6), 285-293$.

Hong, Y. (2019). Becoming global: Global Citizenship Education in Chinese middle schools in a secondtier city. Unpublished doctoral thesis. University of Sydney.

Hong, Y. (2020). Do the conditions in Chinese secondary school education imply a need for global citizenship education? An exploration of six secondary schools in Jiangsu. Asia Pacific Education Review, 21(3), 455-472.

Howard, A., Dickert, P., Owusu, G., \& Riley, D. (2018). In service of the western world: Global citizenship education within a Ghanaian elite context. British Journal of Educational Studies, 66(4), 497-514.

Jerome, L., \& Lalor, J. (2020). Revisiting subject knowledge in citizenship education: Understanding power and agency. Education, Citizenship and Social Justice, 15(2), 104-118.

Kim, M. K. (2015). Cultural difference and shared values: A critical perspective on being a good citizen, East and West. In M. Print \& C. B. Tan (Eds.), Educating "good" citizens in a globalising world for the twenty-first century (pp. 65-80). Sense Publishers.

Kohn, H. (1944). The idea of nationalism: A study of its origins and background. Macmillan Company.

Lee, E. (1997). Chinese American families. In E. Lee (Ed.), Working with Asian Americans: A guide for clinicians (pp. 46-78). Guilford Press.

Lee, W. O., \& Leung, S. W. (2006). Global citizenship education in Hong Kong and Shanghai secondary schools: Ideals, realities and expectations. Citizenship Teaching and Learning, 2(2), 68-84.

Li, Y., Xie, H., \& Shi, J. (2012). Chinese and American children's perceptions of popularity determinants: Cultural differences and behavioral correlates. International Journal of Behavioral Development, 36(6), 420-429.

McKinney, S. J. (2008). Immigrants and religious conflict: Insider accounts of Italian, Lithuanian, and Polish Catholics in Scotland. In M. Peters, A. Britton, \& H. Blee (Eds.), Global citizenship education: Philosophy, theory, and pedagogy (pp. 333-349). Sense Publishers.

Neuman, W. L. (2014). Social research methods: Qualitative and quantitative approaches (7th ed.). Pearson Education.

Niemi, R. G., \& Chapman, C. (1999). Making students good citizens. Education Digest, 65(1), 36.

Niens, U., \& Reilly, J. (2012). Education for global citizenship in a divided society? Young people's views and experiences. Comparative Education, 48(1), 103-118.

Oxfam (2015) Education for Global Citizenship: A guide for schools. http://bit.ly/32Q58kF

Patrick, J. J. (1999). Concepts at the core of education for democratic citizenship. In C. F. Bahmueller \& J. J. Patrick (Eds.), Principles and practices of education for democratic citizenship: International perspectives and projects (pp. 9-68). ERIC Publications.

Print, M. (1993). Curriculum development and design (2nd ed.). Allen \& Unwin. 
Print, M. (2007). Citizenship education and youth participation in democracy. British Journal of Educational Studies, 55(3), 325-345.

Print, M., \& Buchanan, J. (2019). "And its ghost may be heard": Policy and practice in civics and citizenship education in Australia over two decades. In J. Pineda-Alfonso, N. De Alba-Fernández, \& E. NavarroMedina (Eds.), Handbook of research on education for participative citizenship and global prosperity (pp. 89-107). IGI Global.

Raskin, J. D. (2020, October 12). Can humanistic psychology heal the world? Psychology Today. https://www.psychology today.com/us/blog/making-meaning/202010/can-humanistic-psych ology-heal-the-world

Reigeluth, C. M., \& Keller, J. B. (2009). Understanding instruction. In C. M. Reigeluth \& A. A. Carr-Chellman (Eds.), Instructional-design theories and models (Vol. 3, pp. 27-40). Routledge.

Reynolds, R., et al. (2015). One size fits all? Global education for different educational audiences. In R. Reynolds (Ed.), Contesting and constructing international perspectives in global education (pp. 27-41). Sense Publishers.

Ryen, E., \& Jøsok, E. (2021). Citizenship-as-knowledge: How perspectives from Bildung-centred Didaktik can contribute to European citizenship education beyond competence. European Educational Research Journal, 00, 1-19.

Tan, D. L., \& Zhou, M. (2004). Reflections on transformation of learning approaches. Journal of Nanjing Normal University (Social Science), 1(2004), 2-9.

Tarozzi, M., \& Torres, C. A. (2016). Global citizenship education and the crises of multiculturalism: Comparative perspectives. Bloomsbury.

Torney-Purta, J. (2002). The school's role in developing civic engagement: A study of adolescents in twenty-eight countries. Applied Developmental Science, 6(4), 203-212.

Torres, C. A., \& Bosio, E. (2020). Global citizenship education at the crossroads: Globalization, global commons, common good, and critical consciousness. Prospects, 48, 99-113.

UNESCO (2015). Global Citizenship Education: Topics and learning objectives. https://en.unesco.org/ news/global-citizenship-education-topics-and-learning-objectives

Wynveen, C. J., Kyle, G. T., \& Tarrant, M. A. (2012). Study abroad experiences and global citizenship: Fostering proenvironmental behavior. Journal of Studies in International Education, 16(4), 334-352.

Yang, Q. L. (1990). Critiquing the educational view of the classic Confucius humanity: Combining comparison with Western humanity. Social Sciences in China, 4(1990), 147-158.

Yang, X. W. (2004). School reforms in the process of globalisation: A methodological perspective. East China Normal University Press.

Youniss, J., McLellan, J. A., \& Yates, M. (1997). What we know about engendering civic identity. American Behavioral Scientist, 40(5), 620-631.

Yu, T. L. (2014). Education for world citizens in Chinese schools: Moral education in the cosmopolitan age. In K. J. Kennedy, G. P. Fairbrother, \& Z. Z. Zhou (Eds.), Citizenship education in China: Preparing citizens for the "Chinese century" (pp. 85-99). Routledge.

Zhao, Z. Z. (2013). The shaping of citizenship education in a Chinese context. Frontiers of Education in China, 8(1), 105-122.

Zheng, G. X. (2008). Dilemma of the integrated curriculum of practical activity and countermeasures. Research in Educational Development, 2(2008), 83-85. http://bit.ly/3eR3XUF.

Zhou, P. Y. (2011). Localization of the global education. Resources for Research and Learning, 28(5), 5-15.

Publisher's Note Springer Nature remains neutral with regard to jurisdictional claims in published maps and institutional affiliations.

Yi Hong received her bachelor's degree in medical science in 2013 from the University of Bristol, United Kingdom. She earned a master's degree and a PhD in Education from University of Sydney, Australia. Since August 2021, Yi has been a postdoctoral fellow at the School of Education, Soochow University, China. She also serves Oceania Comparative and International Education Society as an intern editor and is responsible for content promotion for its flagship publication, International Education Journal: Comparative Perspectives. Yi's research interests include global citizenship education, moral education, curriculum studies, and cultural studies in education research. 